\title{
Sobrevivência e nodulação do Rhizobium tropici em sementes de feijão tratadas com fungicidas
}

\author{
Survival and nodulation of Rhizobium tropici on common bean seeds treated with fungicides
}

\author{
Ademir Sérgio Ferreira de Araújo ${ }^{1}$ Ricardo Silva Araújo ${ }^{2}$
}

\begin{abstract}
-NOTA-
RESUMO

O objetivo deste trabalho foi avaliar a sobrevivência e a capacidade de nodulação do Rhizobium tropici em sementes de feijão tratadas com fungicidas. $O$ estudo foi realizado em laboratório e em casa de vegetação. Sementes de feijão (Phaseolus vulgaris) foram tratadas com seis diferentes fungicidas e inoculadas com Rhizobium tropici estirpe CIAT 899. A sobrevivência do Rhizobium nas sementes foi avaliada no tempo 0 e 24 horas após o tratamento com fungicidas e a inoculação, utilizando o método do número mais provável

of Rhizobium on seeds was evaluated 0 and 24 hours after treatment with fungicides and inoculation, using the most probable number (MPN) method. The nodulation of common bean thirty days after plant emergence, in plantation conduced 0 and 24 hours after seeds treatment with fungicides and inoculation, was evaluated in soil with population of native Rhizobium. The fungicides harmed the survival of inoculated Rhizobium on seeds and, in plantation conduced 24 hours after seeds treatment, reduced the nodulation of common bean. However, nodules were found in all plants, suggesting nodulation by native Rhizobium of soil.
\end{abstract} (NMP). A nodulação do feijão, em plantio realizado no tempo o e 24 horas após o tratamento com fungicidas, e a inoculação foram avaliadas em solo com população estabelecida de Rhizobium nativo aos trinta dias após a emergência das plantas. A sobrevivência do Rhizobium inoculado nas sementes foi prejudicada pela aplicação dos fungicidas avaliados. A nodulação do feijoeiro foi reduzida pela aplicação dos fungicidas, quando o plantio foi realizado 24 horas após o tratamento das sementes. Entretanto, foram encontrados nódulos em todos os tratamentos, evidenciando que houve nodulação do Rhizobium nativo do solo.

Palavras-chave: fixação de nitrogênio; feijão comum; inoculação.

\section{ABSTRACT}

The aim of this work was to evaluate the survival and nodulation of Rhizobium tropici on common bean seeds treated with fungicides. The study was conduced out at laboratory and greenhouse conditions. Common bean (Phaseolus vulgaris) seeds were treated with six fungicides and inoculated with Rhizobium tropici strain CIAT 899. The survival
Key words: nitrogen fixation; common bean; inoculation.

Dentre as condições necessárias para uma satisfatória produção do feijoeiro, a germinação das sementes e a formação do "stand" no campo são as mais importantes. Em muitos casos, e principalmente em áreas onde a cultura é cultivada todos os anos, torna-se necessário o tratamento de sementes com fungicidas para evitar a incidência de doenças que afetem a cultura (SARTORATO \& RAVA, 1994).

Por outro lado, as recomendações de tratamento de sementes de leguminosas com fungicidas enfrentam uma séria restrição quando se pretende utilizar inoculantes contendo estirpes de Rhizobium (MONTEIRO et al., 1990). Segundo OLIVEIRA et al. (1999), o tratamento das sementes coloca os fungicidas em contato direto com o inoculante, fato que pode ser

${ }^{1}$ Universidade Estadual do Piauí, Campus de Parnaíba, Av. Nossa Senhora de Fátima, s/n, 64202-220, Parnaíba, PI, Brasil. E-mail: asfaruaj@esalq.usp.br. Autor para correspondência.

${ }^{2}$ Katec Agro-Técnica Ltda., Rua 21, Q 78A, Lt 8/9, 74911-200, Aparecida de Goiania, GO, Brasil. 
prejudicial à sobrevivência do inóculo, pelos possíveis efeitos nocivos do princípio ativo do produto. Entretanto, segundo ISOI \& YOSHIDA (1988), o efeito biológico do tratamento de sementes de leguminosas dependerá da dose do fungicida aplicado, da estirpe de Rhizobium utilizada, de fatores climáticos e de outros microrganismos existentes na rizosfera. Esse efeito pode ser depressivo, podendo ainda não influenciar ou, até mesmo, incrementar os fatores produtivos da cultura. TU (1981) avaliou o efeito de cinco fungicidas (Benomyl, Captan, Maneb, Thiram, Zineb) em sementes de alfafa, e observou que o Thiram foi tóxico para o crescimento da bactéria em placa de Petri. Em relação ao desenvolvimento das plantas em vasos, observou que elevados níveis de fungicidas suprimiram a sua nodulação, quando comparadas com plantas não tratadas ou tratadas com dosagens baixas. O objetivo deste trabalho foi avaliar a sobrevivência e a nodulação do Rhizobium tropici em sementes de feijão tratadas com fungicidas.

Os experimentos foram conduzidos em laboratório e em casa de vegetação. Foram utilizados oito tratamentos e dois períodos de avaliação. Os tratamentos consistiram de: Inoculação com Rhizobium ( $\left.\mathrm{T}_{1}\right)$; Inoculação + Benlate $\left(\mathrm{T}_{2}\right)$; Inoculação + Captan ( $\left.\mathrm{T}_{3}\right)$; Inoculação + Vitavax $\left(\mathrm{T}_{4}\right)$; Inoculação + Rhodiauran $\left(\mathrm{T}_{5}\right)$; Inoculação + Terraclor $\left(\mathrm{T}_{6}\right)$; Inoculação + Vitavax-Thiran $\left(\mathrm{T}_{7}\right)$; Testemunha sem inoculação e sem fungicida $\left(\mathrm{T}_{8}\right)$. As doses dos fungicidas foram determinadas segundo EMBRAPA (1996). As sementes do cultivar aporé de feijão foram desinfestadas conforme VINCENT (1970). Utilizaramse $100 \mathrm{~g}$ de sementes, para cada tratamento, que foram colocadas em sacos plásticos transparentes. Os fungicidas foram misturados às sementes em cada saco, as quais, em seguida, foram deixadas para secar à temperatura ambiente. Posteriormente foi adicionado em cada saco $1 \mathrm{~g}$ de inoculante à base de turfa, contendo a estirpe CIAT 899 na concentração de $10^{8} \mathrm{Cel}$ $\mathrm{mL}^{-1}$, com a adição de $10 \mathrm{~mL}$ de solução açucarada a $12 \%$.

No primeiro experimento, em laboratório, foram retiradas três amostras de 50 sementes de cada saco plástico (imediatamente após o tratamento das sementes com fungicidas e inoculação), que foram transferidas para frascos contendo $50 \mathrm{~mL}$ de água estéril. Os frascos foram agitados por 30 minutos e, ao final, foram feitas quatro diluições decimais. Uma alíquota de $1 \mathrm{ml}$ de cada diluição foi transferida para placa de Petri contendo meio de cultura agar-levedura-manitol (YM) esterilizado, com adição de 100ppm de espectionimicina. O mesmo procedimento foi realizado 24 horas após o tratamento das sementes com fungicidas e inoculação com Rhizobium. As placas de Petri foram incubadas a $28 \pm 1^{\circ} \mathrm{C}$ por 72 horas e, ao final deste período, foi realizada a avaliação do número mais provável (NMP) de Rhizobium, conforme ANDRADE \& HAMAKAWA(1995).

No segundo experimento, em casa de vegetação, foi utilizado um Argissolo Vermelho Amarelo contendo uma população estabelecida de Rhizobium de 5,8 $\times 10^{6}$ células $\mathrm{g}^{-1}$ de solo (estimada pela técnica do NMP). A amostra do solo apresentou as seguintes características químicas: $\mathrm{pH}, 5,7 ; \mathrm{P}, 12 \mathrm{mg} \mathrm{dm}^{-3} ; \mathrm{K}, 0,9$; Ca, 7; Mg, 5 e CTC, 47mmol kg-1. As sementes de feijão, do mesmo cultivar, foram plantadas em sacos plásticos contendo $2 \mathrm{~kg}$ de solo. O primeiro plantio foi realizado imediatamente após o tratamento das sementes com os fungicidas e a inoculação com o Rhizobium. O segundo plantio foi realizado 24 horas após o primeiro. Foram utilizadas seis sementes por saco e, após cinco dias da emergência das plantas, procedeu-se o desbaste, deixando-se duas plantas por saco. A colheita das plantas foi realizada aos 30 dias após a emergência (DAE), separando-se a parte aérea do sistema radicular. Os nódulos foram destacados das raízes, colocados para secar a $65^{\circ} \mathrm{C}$, sendo em seguida pesados e contados. O delineamento experimental foi inteiramente casualizado com seis repetições. Os dados foram submetidos à análise de variância (ANOVA), sendo as médias comparadas pelo teste de Tukey a $5 \%$ de probabilidade de erro.

A sobrevivência da estirpe de Rhizobium tropici inoculada foi afetada negativamente por todos os fungicidas utilizados no tratamento das sementes tanto no tempo zero como após 24 horas do contato do inoculante com o fungicida (Tabela 1). A exceção deveuse ao fungicida Vitavax-Thiram, que não apresentou efeito negativo na sobrevivência da bactéria comparado ao controle, 24 horas após o tratamento das sementes. Por outro lado, os fungicidas Benlate e Vitavax ocasionaram a morte de todas as células da estirpe inoculada nas duas avaliações. Já o fungicida Captan provocou a morte das células após 24 horas do contato do inoculante com o fungicida. Em outros trabalhos, já havia sido relatado que o fungicida Benlate é um dos maiores causadores de mortalidade da bactéria inoculada nas sementes (MONTEIRO et al., 1990; RAMOS \& RIBEIRO, 1993), enquanto que o fungicida Captan tem-se mostrado bastante tóxico ao Rhizobium (VARGAS et al., 2004). De uma forma geral, a taxa de sobrevivência da bactéria inoculada diminuiu após 24 horas da inoculação, exceto para os tratamentos com os fungicidas Rhodiauram e Vitavax-Thiram. Resultados semelhantes foram encontrados por MONTEIRO et al. (1990), que observaram a diminuição da sobrevivência 
Tabela 1 - Sobrevivência do Rhizobium tropici inoculado em sementes de feijão tratadas com fungicidas ${ }^{(1)}$

\begin{tabular}{lcc}
\hline Tratamento & 0 hora (cel semente ${ }^{-1}$ ) & 24 horas $\left(\right.$ cel semente $^{-1}$ ) \\
\hline Inoculação & $1,3 \times 10^{5} \mathrm{aA}$ & $2,7 \times 10^{4} \mathrm{aB}$ \\
Inoc + Benlate 500 & 0 & 0 \\
Inoc + Captan 750 TS & $1,0 \times 10^{3} \mathrm{~b}$ & 0 \\
Inoc + Vitavax 750 PM & 0 & 0 \\
Inoc + Rhodiauran 700 & $8,3 \times 10^{2} \mathrm{cB}$ & $5,5 \times 10^{3} \mathrm{bA}$ \\
Inoc + Terraclor 750 PM & $4,0 \times 10^{3} \mathrm{bA}$ & $1,0 \times 10^{2} \mathrm{cB}$ \\
Inoc + Vitavax-Thiram PM & $5,2 \times 10^{2} \mathrm{cB}$ & $2,7 \times 10^{4} \mathrm{aA}$ \\
\hline CV (\%) & 14,3 & 18,1 \\
\hline
\end{tabular}

${ }^{(1)}$ Médias não seguidas pelas mesmas letras minúsculas, na coluna, e maiúsculas, na linha, diferem entre si pelo teste de Tukey a 5\% de probabilidade de erro.

do Rhizobium após 24 horas do contato do inoculante com o fungicida.

Os efeitos dos fungicidas sobre a nodulação do feijoeiro foram diferentes dos observados na sobrevivência do Rhizobium. Não houve diferenças significativas no número e na massa dos nódulos entre os tratamentos avaliados (plantio realizado após o tratamento das sementes com fungicidas e inoculação). As exceções deveram-se aos tratamentos com os fungicidas Rhodiauran, que apresentaram diminuição no número e na massa dos nódulos, Vitavax-Thiram e a testemunha, que apresentaram uma diminuição na massa dos nódulos. Houve uma diminuição significativa no número e na massa dos nódulos para o plantio realizado após 24 horas da inoculação entre os tratamentos com fungicidas, quando comparados ao tratamento somente com a inoculação e a testemunha (Tabela 2).
Para os fungicidas Thiram e Captan, esses resultados foram semelhantes aos encontrados por GRAHAM et al. (1980), que observaram uma redução na sobrevivência do Rhizobium phaseoli em placas de Petri e em plantas de feijão no campo com a utilização destes fungicidas, quando o plantio havia sido realizado 24 horas após a inoculação, não havendo redução nestas variáveis no plantio imediatamente após a inoculação. Observa-se, neste trabalho, que houve uma boa nodulação do feijoeiro e isso sugere que, nos tratamentos que apresentaram diminuição ou mortalidade das células rizobianas inoculadas (Tabela 1), a nodulação apresentada foi devida ao Rhizobium nativo do solo.

De acordo com os resultados observados, existe uma dificuldade de compatibilizaçao do uso de inoculantes com fungicidas e, neste caso, segundo HUNGRIA et al. (2001), torna-se necessário avaliar cada situação. Segundo os mesmos autores, a utilização de

Tabela 2 - Número e massa dos nódulos secos do feijoeiro submetidos ao tratamento de sementes com fungicidas e inoculação com a estirpe Rhizobium tropici CIAT 899.

\begin{tabular}{|c|c|c|c|c|}
\hline \multirow[t]{2}{*}{ Tratamento } & \multicolumn{2}{|c|}{$\begin{array}{l}\text { Número de nódulos } \\
\qquad\left(\mathrm{n}^{\circ} \mathrm{pl}^{-1}\right)\end{array}$} & \multicolumn{2}{|c|}{$\begin{array}{l}\text { Massa dos nódulos secos } \\
\qquad\left(\mathrm{mg} \mathrm{pl}^{-1}\right)\end{array}$} \\
\hline & 0 hora & 24 horas & 0 hora & 24 horas \\
\hline Testemunha & $46 \mathrm{aA}$ & $42 \mathrm{aA}$ & $37,37 \mathrm{bA}$ & 42,55 aA \\
\hline Inoculação & $51 \mathrm{aA}$ & $40 \mathrm{aB}$ & $50,26 \mathrm{aA}$ & $43,86 \mathrm{aB}$ \\
\hline Inoc + Benlate 500 & $47 \mathrm{aA}$ & $31 \mathrm{bB}$ & $49,50 \mathrm{aA}$ & $33,36 \mathrm{bB}$ \\
\hline Inoc + Captan 750 TS & $51 \mathrm{aA}$ & $37 \mathrm{bB}$ & $47,64 \mathrm{aA}$ & $37,95 \mathrm{bB}$ \\
\hline Inoc + Vitavax 750 PM & $42 \mathrm{abA}$ & 35 bB & 43,17 aA & $36,63 \mathrm{bB}$ \\
\hline Inoc + Rhodiauran 700 & 39 bA & $30 \mathrm{bB}$ & $35,59 \mathrm{bA}$ & $34,13 \mathrm{bA}$ \\
\hline Inoc + Terraclor 750 PM & $48 \mathrm{aA}$ & 35 bB & $52,96 \mathrm{aA}$ & $37,73 \mathrm{bB}$ \\
\hline Inoc + Vitavax-Thiram PM & $46 \mathrm{aA}$ & $32 \mathrm{bB}$ & $38,41 \mathrm{bA}$ & $31,73 \mathrm{bB}$ \\
\hline $\mathrm{CV}(\%)$ & 19,0 & 17,7 & 12,1 & 14,9 \\
\hline
\end{tabular}
${ }^{(1)}$ Médias não seguidas pelas mesmas letras minúsculas, na coluna, e maiúsculas, na linha, diferem entre si pelo teste de Tukey a 5\% de
probabilidade de erro.

Ciência Rural, v.36, n.3, mai-jun, 2006. 
sementes com alta qualidade fisiológica e fitossanitária deve ser recomendada nestes casos. Se as sementes forem de boa qualidade, as condições de umidade do solo forem favoráveis e as áreas em questão não apresentaram histórico de doenças, deve-se evitar o uso de fungicidas (CAMPO \& HUNGRIA, 2000). Em caso contrário, segundo os autores, deve-se dar preferência a fungicidas menos tóxicos. De qualquer forma, uma boa nodulação depende de um grande número de células viáveis; portanto, na presença de fungicidas, o aumento na dosagem do inoculante proporciona um número maior de células nas sementes (VARGAS et al., 2004).

A sobrevivência do Rhizobium inoculado nas sementes foi prejudicada pela aplicação dos fungicidas avaliados. A nodulação do feijoeiro foi reduzida pela aplicação dos fungicidas quando o plantio foi realizado 24 horas após o tratamento das sementes. Os fungicidas Benlate e Vitavax foram os mais prejudiciais à bactéria inoculada nas sementes.

\section{REFERÊNCIAS}

ANDRADE, D.S.; HAMAKAWA, P.J. Estimativa do número de células viáveis de rizóbio no solo e em inoculantes por infecção em plantas. In: HUNGRIA, M.; ARAUJO, R.S. (Eds). Manual de métodos empregados em estudos de microbiologia agrícola. Brasília: Embrapa-SPI, 1994. p.63-94. CNPSo, 1995. p.398-402.

CAMPO, R.J.; HUNGRIA, M. Compatibilidade do uso de inoculantes e fungicidas no tratamento de sementes de soja. Londrina: Embrapa-Soja, 2000. 31p.

EMBRAPA, Centro Nacional de Pesquisa de Arroz e Feijão. Recomendações técnicas para a cultura do feijão. Brasília: SPI, 1996. 32p.
GRAHAM, P.H. et al. Survival of Rhizobium phaseoli in contact with chemical seed protectant. Agronomy Journal, v.72, p.625-627, 1980.

HUNGRIA, M. et al. Fixação biológica do nitrogênio na cultura da soja. Londrina: Embrapa-Soja, 2001. 48p.

ISOI, T.; YOSHIDA, S. Effect of Thiram (TetramethylThiuram-Disulphide) application on nodulation in soybean and kidney bean plants: observation using the root-box-culture technique. Soil Science and Plant Nutrition, v.34, n.4, p.633-637, 1988.

MONTEIRO, R.T.R. et al. Sobrevivência de Rhizobium leguminosarum bv phaseoli em sementes tratadas com fungicidas. Revista de Microbiologia, v.21, p.55-59, 1990.

OLIVEIRA, P.P.A. et al. Interação entre cultivares, estirpes comerciais de Rhizobium meliloti e fungicidas no incremento da produção de alfafa. Pesquisa Agropecuária Brasileira, v.34, n.3, p.425-431, 1999.

RAMOS, M.L.G.; RIBEIRO JR, W.Q. Effect of fungicide on survival of Rhizobium on seeds and the nodulation of bean (Phaseolus vulgaris L.). Plant and Soil, v.152, p.145-150, 1993.

SARTORATO, A.; RAVA, C.A. Principais doenças do feijoeiro comum e seu controle. Brasília: EMBRAPA-SPI, 1994. 300p.

TU, C.M. Effect of fungicidal seed treatments on alfalfa growth and nodulation by Rhizobium meliloti. Chemosphere, v.10, p.127-134, 1981.

VARGAS, M.A.T. et al. Inoculação de leguminosas e manejo de adubos verdes. In: SOUSA, D.M.G.; LOBATO, E. (Eds) Cerrado: correção do solo e adubação. Brasília: Embrapa, 2004. p.97-128.

VINCENT, J.M. A manual for the practical study of root nodule bacteria. Oxford: Blackwell, 1970. 119p. 